\title{
Gas and gas hydrate distribution around seafloor seeps in Mississippi Canyon, Northern Gulf of Mexico, using multi-resolution seismic imagery
}

\author{
Warren T. Wood ${ }^{\mathrm{a}, *}$, Patrick E. Hart ${ }^{\mathrm{b}}$, Deborah R. Hutchinson ${ }^{\mathrm{c}}$, Nader Dutta ${ }^{\mathrm{d}}$, Fred Snyder ${ }^{\mathrm{d}}$, \\ Richard B. Coffin ${ }^{\mathrm{e}}$, Joseph F. Gettrust ${ }^{\mathrm{a}}$ \\ ${ }^{a}$ U.S. Naval Research Laboratory, Code 7432, Stennis Space Center, MS 39529, USA \\ ${ }^{\mathrm{b}}$ U.S. Geological Survey, Menlo Park, CA 94025, USA \\ ${ }^{c}$ U.S. Geological Survey, Woods Hole, MA 02543, USA \\ ${ }^{\mathrm{d}}$ Schlumberger Reservoir Services/Data \& Consulting Services, 10001 Richmond Avenue, Houston, TX 77042, USA \\ ${ }^{\mathrm{e}}$ U.S. Naval Research Laboratory, Code 6114, Washington, DC 20375, USA
}

\section{A R T I C L E I N F O}

\section{Article history:}

Received 29 March 2007

Received in revised form 18 June 2007

Accepted 4 January 2008

Keywords:

Methane hydrate

Seafloor seep

\begin{abstract}
A B S T R A C T
To determine the impact of seeps and focused flow on the occurrence of shallow gas hydrates, several seafloor mounds in the Atwater Valley lease area of the Gulf of Mexico were surveyed with a wide range of seismic frequencies. Seismic data were acquired with a deep-towed, Helmholz resonator source $(220-820 \mathrm{~Hz})$; a high-resolution, Generator-Injector air-gun $(30-300 \mathrm{~Hz})$; and an industrial air-gun array $(10-130 \mathrm{~Hz})$. Each showed a significantly different response in this weakly reflective, highly faulted area. Seismic modeling and observations of reversed-polarity reflections and small scale diffractions are consistent with a model of methane transport dominated regionally by diffusion but punctuated by intense upward advection responsible for the bathymetric mounds, as well as likely advection along pervasive filamentous fractures away from the mounds.
\end{abstract}

Published by Elsevier Ltd.

\section{Introduction}

Processes of methane generation, transport, and storage as gas or gas hydrate in shallow seafloor sediments are critically important for chemosynthetic communities (Sassen et al., 1999) and possibly also for climate change (Dickens et al., 1997; Kennett et al., 2002). A crucial aspect to the availability of methane at the seafloor (and potential release via bottom water warming) is the distribution of gas and gas hydrate in the sediments surrounding seafloor seeps, where the highest concentrations of methane are found (e.g., Brooks et al., 1984). Constraining the distribution of gas and gas hydrate at well-studied seafloor mounds in the northern Gulf of Mexico is the subject of this investigation.

\subsection{Area}

The Gulf of Mexico is well known for seafloor methane hydrate accumulations associated with hydrocarbon seeps (e.g., Brooks et al., 1984; MacDonald et al., 1994), and it is well known, at least in a gross sense, that faults provide conduits for the expulsion of pore fluid (Roberts et al., 1996). It is these hydrologic processes that are

\footnotetext{
* Corresponding author. Tel.: +1 228688 5311; fax: +1 2286885752 .

E-mail address: warren.wood@nrlssc.navy.mil (W.T. Wood).
}

of interest in this study. Depending on the flux, the methane-laden fluids associated with these expulsions form mounds of mud, calcium carbonate (via cycling of the methane carbon), or gas hydrate (Roberts and Carney, 1997). Long-term monitoring data are rare, but year-long records from Bush Hill, a high-volume seep in Green Canyon 185 in $~ 550 \mathrm{~m}$ deep water, show no significant changes in the size or appearance of the gas hydrate mound. Thermal variations during the observation were dominated only by tides (Vardaro et al., 2005). However, episodes of fluid and/or methane expulsion may be highly variable in time and space (Roberts and Carney, 1997), making extrapolation to other sites, or even other times at the same site, difficult.

The sites selected for this investigation are several seafloor mounds associated with seeps in Atwater Valley lease blocks 13 and 14. The mounds lie on the relatively flat seafloor of the Mississippi Canyon (Fig. 1), many hundreds of meters above an active salt diapir. A faulted seafloor is evident in the shaded bathymetry (Fig. 1) and is shown in even greater detail in side-scan data (Hart et al., 2008). Each mound is visible in the shaded bathymetry as a quasi-circular bathymetric mound $5-10 \mathrm{~m}$ in height and several hundred meters across. The Mississippi Canyon is likely a site of active downslope (north to south) sediment transport, which may be either erosional or depositional at any given time and location. Mounds D, E, and F are in a distal part of the canyon where we expect mostly fine-grained sediments. 


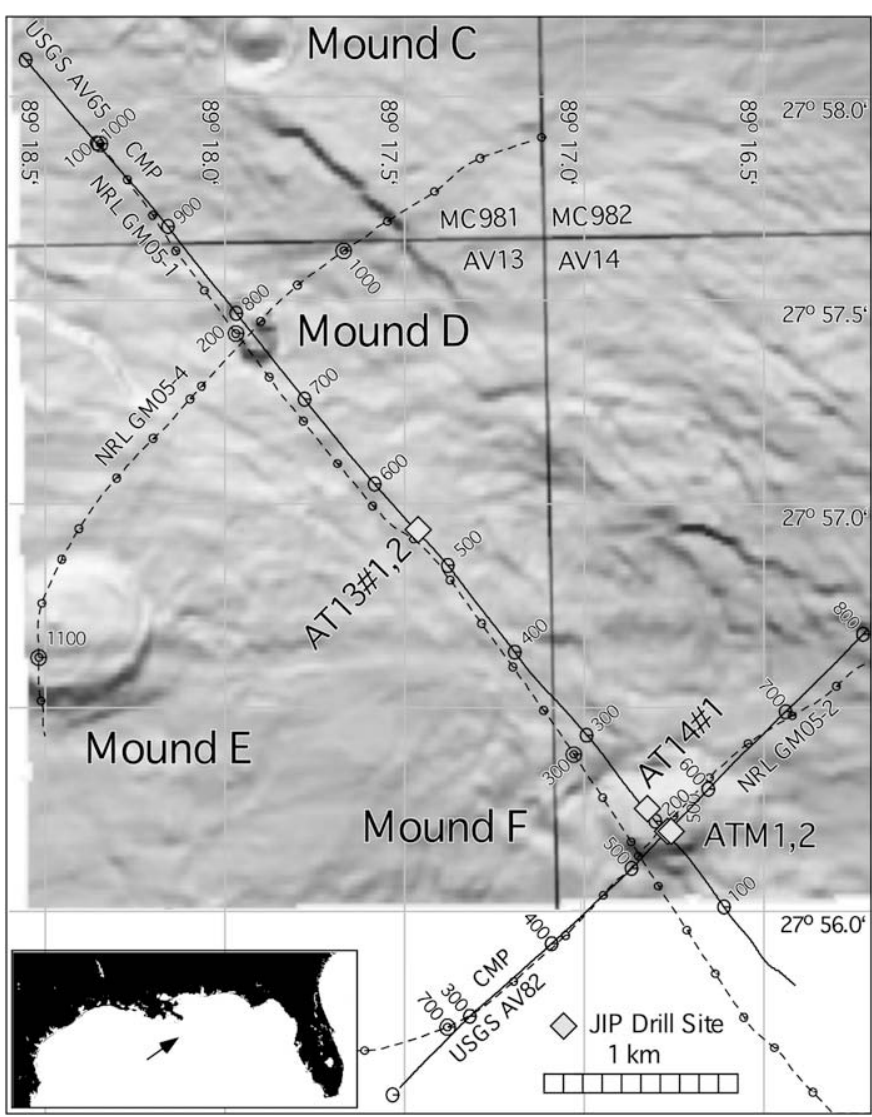

Fig. 1. The Atwater Valley area lies in the relatively flat floor of Mississippi Canyon at $\sim 1300 \mathrm{~m}$ water depth in the Gulf of Mexico (inset). GI-gun track lines AV65 and AV82 (solid lines) cross at Mound F. DTAGS track lines (dashed) GM05-1 and GM05-2 cross just off Mound F, GM05-1 and GM05-4 intersect at Mound D, and GM04-4 crosses Mound E.

Chemical and thermal anomalies associated with these mounds (Coffin et al., 2006) show that Mound F is associated with seafloor emission of highly saline and methane rich fluid. Strong thermal anomalies at both mounds indicate localized fluid flux at these locations (Coffin et al., 2006). Isotopic evidence for intercalated younger and older sediment suggests the mud on Mound $\mathrm{F}$ has been redeposited by numerous expulsion episodes. In 2005, the transect between Mounds D and F was drilled in several locations (squares in Fig. 1) by the Chevron Joint Industry Program (Claypool, 2006).

\subsection{Approach}

Our approach was to acquire and analyze three specialized seismic data sets, spanning a wide range of frequencies, to infer the spatial distribution of gas and gas hydrate immediately around the selected sites. Our interpretation relies on the well-known observation that even small amounts of free gas have a strong effect on seismic propagation (Domenico, 1974), and are effective scatterers of seismic energy. Our approach also included identifying sharp, lateral changes in reflectivity that could be attributed to changes in pore filling material (e.g., water to gas, or water to gas hydrate). The details of the assumptions required for this approach are discussed more fully below.

It is also well known that methane is stable as a solid-phase methane hydrate under the equilibrium pressure and temperature conditions expected in the shallow sediments in Atwater Valley 13/ 14. Assuming the approximate equilibrium curve of Brown et al. (1996), a water depth of $1300 \mathrm{~m}$, bottom water temperature of
$277.5 \mathrm{~K}$, and a constant geothermal gradient of $43 \mathrm{mK} \mathrm{m}^{-1}$ (Coffin et al., 2006), we expect the regional base of gas hydrate stability (BGHS) to lie at 258 mbsf (Figs. 2-6). In areas where heat flux is dominantly conductive, solute transport is dominantly diffusive, and both are steady state, we expect the BGHS to be nearly parallel to the seafloor with any associated gas resulting in a bottom simulating reflector (BSR). We assume that mismatch between the background, regional or expected BGHS in Figs. 2-6 and BSRs observed in the seismic sections will be caused mostly by upwardly advecting, warm and/or saline fluids (Wood et al., 2002). Imperfect depth conversion of the seismic profiles could also result in events being labeled too shallow by up to a few tens of meters, but this shift is laterally consistent, whereas that associated with upward advection of warm fluids would not be.

The presence of free gas well above the expected regional BGHS can be used not only to indicate the presence of methane saturated

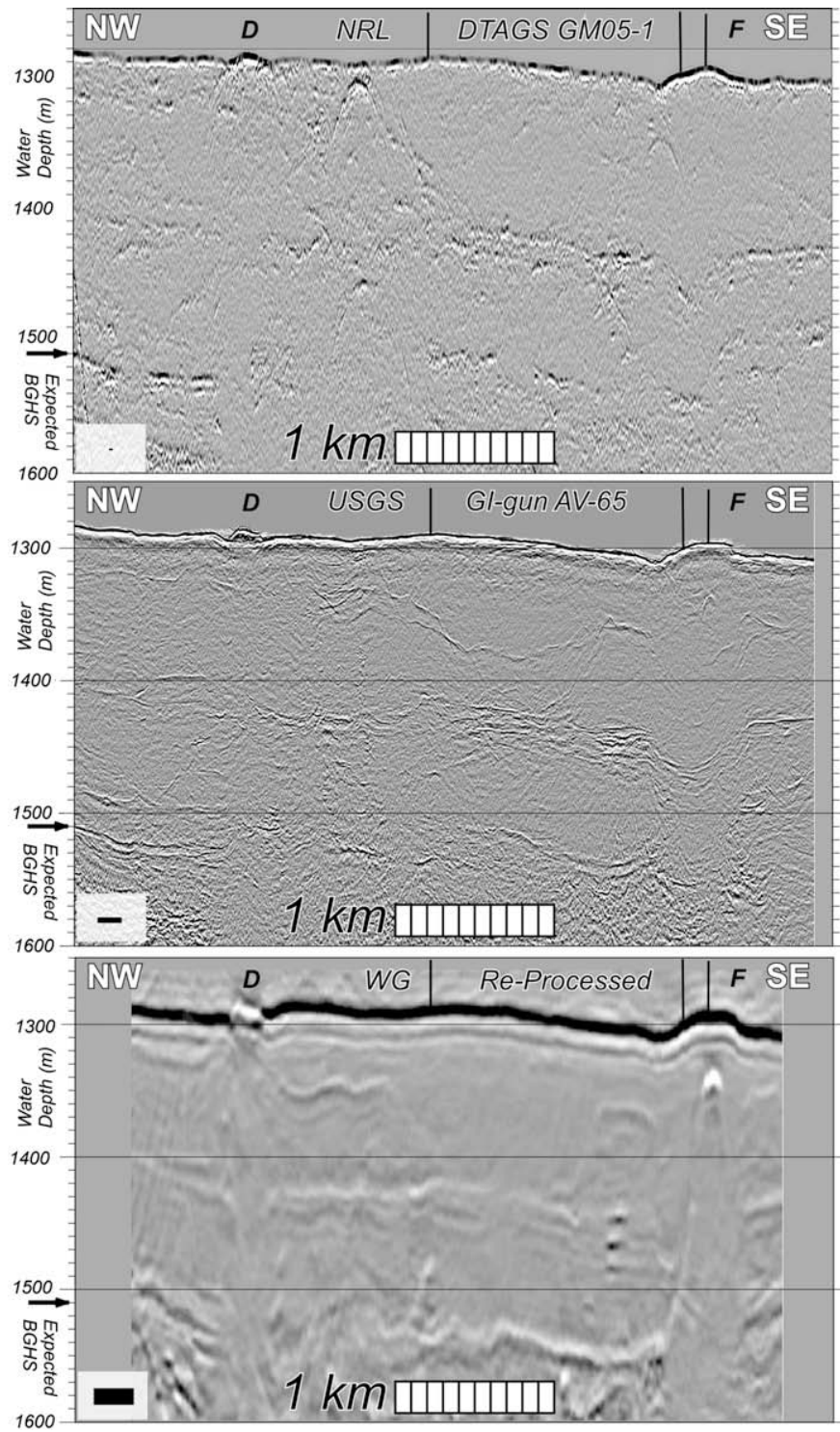

Fig. 2. Seismic transects were acquired using DTAGS (top), GI-gun (center) and large air-gun array (bottom). The transect of the large air-gun array is coincident with USGS GI-gun track AV65. Vertical lines at the seafloor indicate JIP drilling locations. The expected depth to the BGHS, indicated with arrows, appears to be perturbed upward below Mounds D and F. The filled rectangles at lower left in each panel have the width of the first Fresnel zone and height equal to one-half wavelength. For clarity at this scale the DTAGS display is the time derivative of the envelope of the data (not full resolution). 


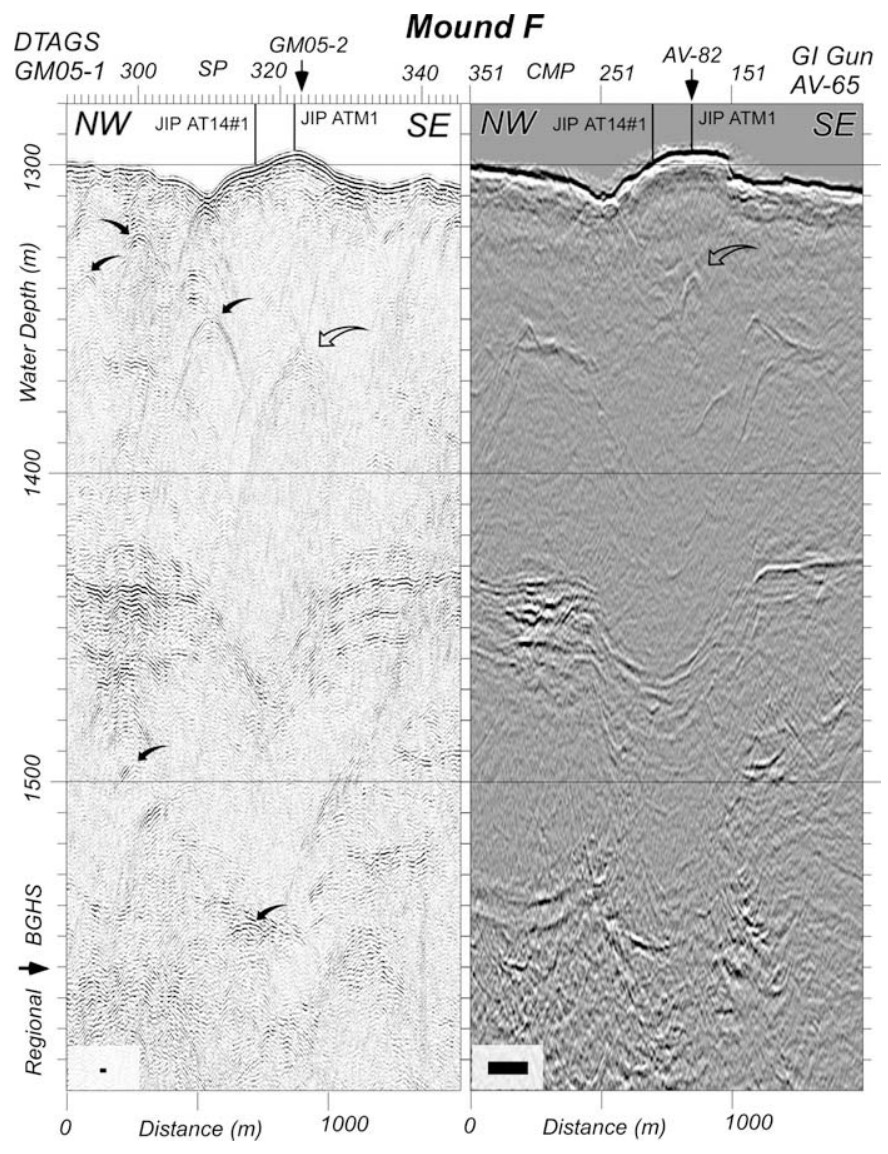

Fig. 3. The distinct pushdown of reflections passing below the mound from 1433$1466 \mathrm{~m}$ depth in both of these profiles not only indicates the presence of gas at some point shallower in the section, but also that mud expulsion does not obscure or destroy stratigraphic structure at this depth.

pore water, but also to constrain the spatial extent of (1) a dynamic, non-equilibrium gas/gas-hydrate system; (2) an advective methane transport system; (3) higher than expected temperatures; and/or (4) higher than expected salinity. In this way seismic images can be used to infer gas hydrate stability, and to some extent, fluid flux. Also, Coffin et al. (2008) observed only methane on and around Mound F, so we assume all gas throughout the observed section is dominantly methane.

The gas-hydrate equilibrium curve is also sensitive to pressure. Although the overpressure responsible for fluid expulsion at seafloor seeps may increase the stability of gas hydrate, we assume that the pressure dissipates rapidly between expulsion episodes within this apparently permeable system, and/or is localized to a narrow conduit. We assume that the pressure is not likely to vary significantly from hydrostatic in the shallow $(<500 \mathrm{~m})$ section and that differential pressure cannot be meaningfully constrained by the presence or absence of free gas.

\section{Methods}

The seismic data analyzed here were acquired by a deep-towed acoustics/geophysics system (DTAGS, Wood et al., 2003) using a solid-state Helmholz resonator source $(220-820 \mathrm{~Hz})$ and a single, high-resolution, 13 in $^{3}$ Generator-Injector (GI) air-gun $(30-300 \mathrm{~Hz}$, Hutchinson and Hart, 2004). These two data sets supplement the existing 3D industrial data set acquired by Western-Geco (WG) with a large air-gun array $(10-130 \mathrm{~Hz})$. For ease of interpretation, and to avoid changing the apparent frequencies with differential

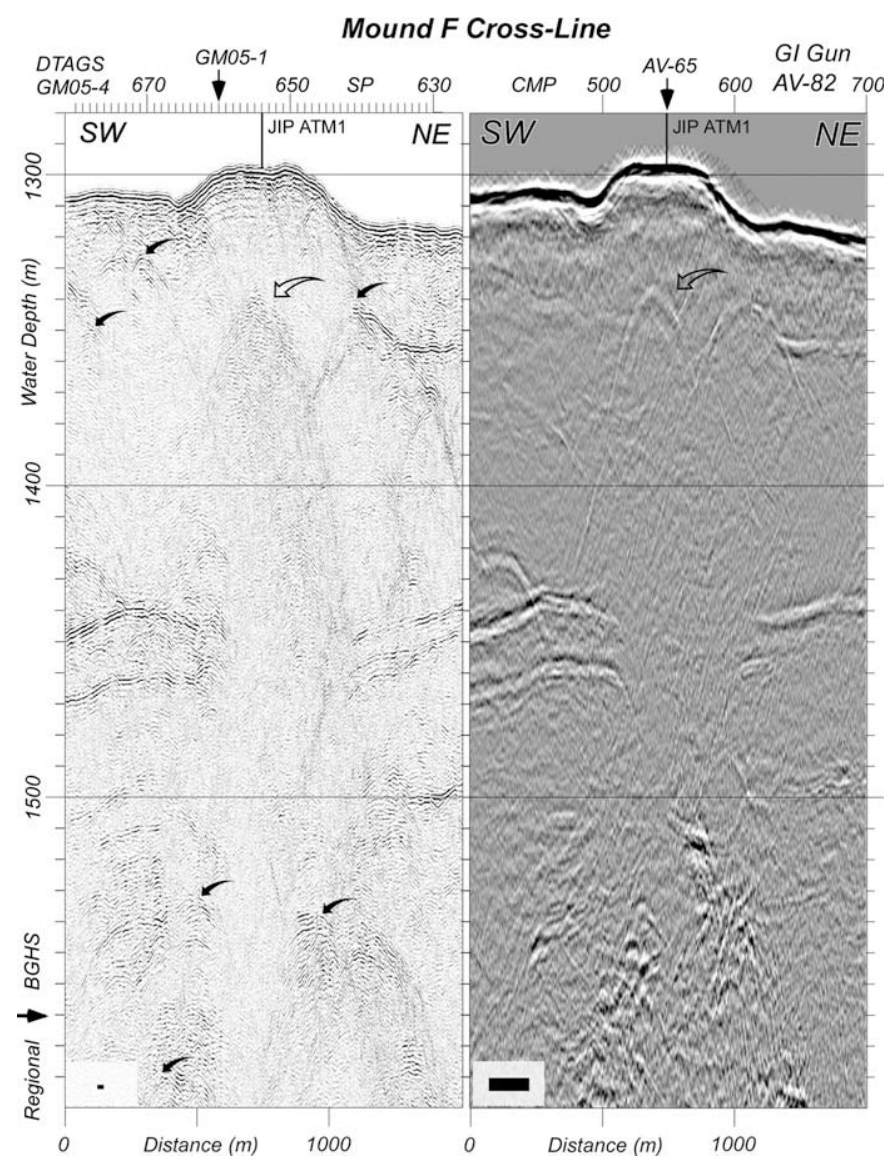

Fig. 4. The apex of the apparent gas accumulation below the mound lies at $1340 \mathrm{~m}$ depth (open arrow) and appears similarly shaped in both the unmigrated (DTAGS, left) and migrated (GI-gun, right) data. Major reflectors are seen in both sections, and a few small diffractions possibly due to highly localized gas accumulation are visible throughout the DTAGS section, even in the shallow sediments (e.g., the southwestern portion between the seafloor and $1330 \mathrm{~m}$ depth) well above the estimated depth of the regional BGHS.

stretch, all seismic images here were converted to depth using a constant velocity of $1500 \mathrm{~m} \mathrm{~s}^{-1}$. Track lines in Fig. 1 show relevant seismic lines, common midpoints (CMP), and shot locations from the GI-gun and DTAGS surveys.

The 3D WG data used here were first presented by Snyder et al. (2004) and were reprocessed at higher resolution than the 3D data available commercially. The DTAGS system was towed at an altitude of 100-150 $\mathrm{m}$ above the seafloor; at a speed that resulted in a single fold "footprint" image with traces $1.5 \mathrm{~m}$ apart (Wood and Gettrust, 2001). Because coherent processing procedures like migration require knowledge of each source and receiver position to within one-quarter wavelength of the highest frequencies $(\sim 0.4 \mathrm{~m}$ in our case), no migration has been applied to the DTAGS images. In the DTAGS images, diffraction hyperbolas are interpreted as abrupt lateral changes in reflectivity.

The lateral resolution of seismic reflection data is limited by the diameter of the first Fresnel zone (e.g., Hilterman, 1982), which for vertically traveling waves is a circular area within which the seismic energy is averaged and coherently reflected back toward the receiver. For the WG data we assume a central frequency of $60 \mathrm{~Hz}$, an altitude of $1300 \mathrm{~m}$, and a sound speed of $1500 \mathrm{~m} \mathrm{~s}^{-1}$, yielding a Fresnel-zone diameter of $255 \mathrm{~m}$. Similarly for the GI-gun data we calculate a Fresnel zone of $151 \mathrm{~m}$ assuming a center frequency of $170 \mathrm{~Hz}$. For DTAGS we use $520 \mathrm{~Hz}$ and an altitude of $100 \mathrm{~m}$ to get a Fresnel-zone diameter of $24 \mathrm{~m}$. The vertical resolution of each system is limited by the wavelength. Assuming a sound speed of 


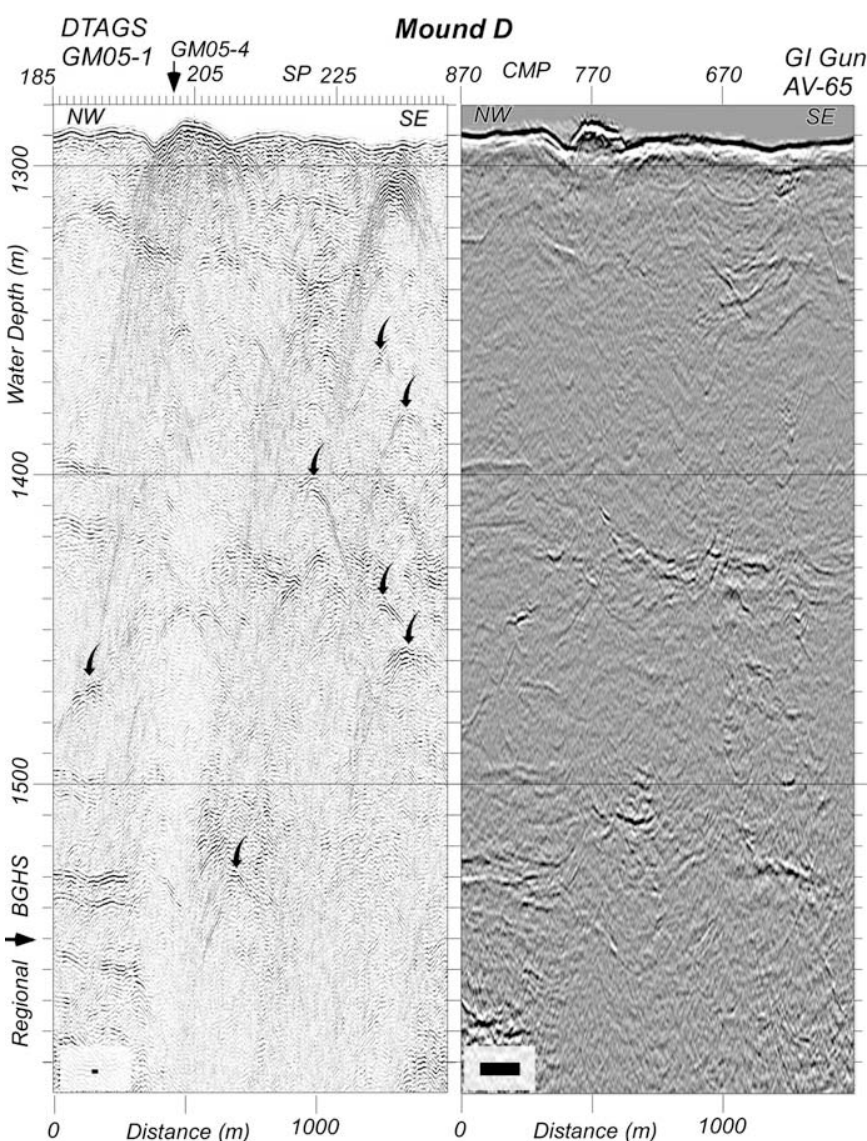

Fig. 5. The seafloor expression of Mound D appears quite rough, resulting in a series of diffractions in the DTAGS data not seen at other mounds. These diffractions are similar to those exhibited by a laterally limited apparent gas accumulation southeast of Mound $\mathrm{D}$ at shot points 233 and $1305 \mathrm{~m}$ depth. There is no coherent, top-of-gas reflection resolvable directly below the mound in either DTGAS or GI-gun section.

$1500 \mathrm{~m} \mathrm{~s}^{-1}$, and the frequencies above, we get values for one-half wavelength of $12.5,4.4$, and $1.4 \mathrm{~m}$ for the WG, GI-gun, and DTAGS data, respectively.

The resolution of each system is represented graphically by a filled rectangle in the lower left corner of each panel in Figs. 2-6. Note that changes in the section can occur over regions smaller than the filled rectangles; these measures are not thresholds of detection for changes in the sediments, but represent a volume over which significant averaging occurs.

\section{Results}

Fig. 2 shows each data set acquired along the drilling transect between mounds labeled D and F. Figs. 3-6 show the portions of seismic profiles through each of Mounds D, E, F, including crosslines where available.

\subsection{Mound $F$}

Immediately apparent in Fig. 2 is the reversed-polarity, bellshaped reflector directly below Mound $F$ in the WG data. The reflector's strength increases upward and is maximal at its apex $\sim 40 \mathrm{~m}$ below the seafloor (mbsf). This bell-shaped reflector is likely a gas accumulation resulting from a perturbation to the BGHS caused by advection of warm pore fluids (Wood et al., 2002, 2004; Snyder et al., 2004). The reflector flares outward at a depth of $1540 \mathrm{~m}$, in the opposite direction of what would be expected from an artifact of migration, and is therefore unlikely to be a residual

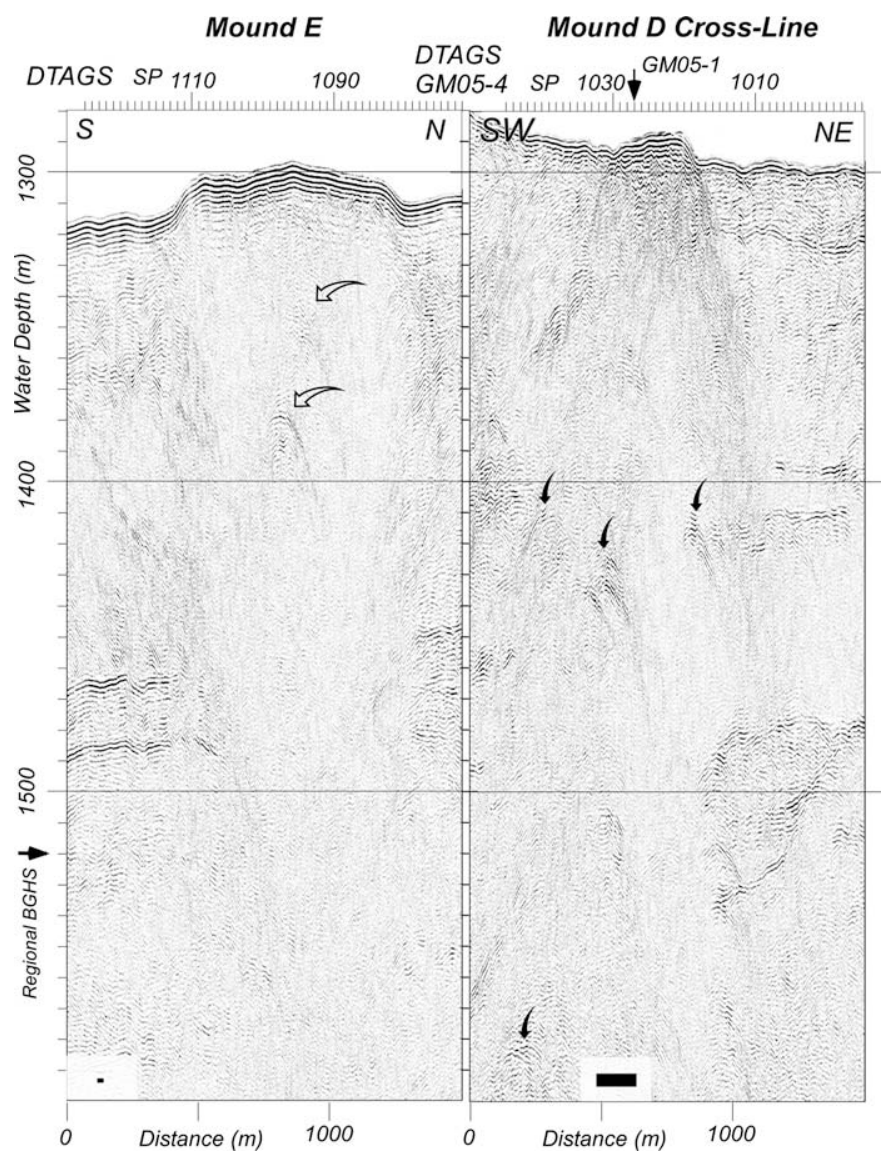

Fig. 6. (Left) Like Mound F, Mound E exhibits a smooth seafloor with two apparent gas accumulations directly below the mound (at 1340, and $1380 \mathrm{~m}$ depth). (Right) The NESW profile through Mound D exhibits similar diffractions (solid arrows) to those seen in the NW-SE profile (Fig. 5), both at the mound surface and throughout the section.

artifact in this migrated section. The base of this flare corresponds to a bright (albeit laterally intermittent), reversed-polarity reflection at the approximate depth of the expected regional BGHS and will be referred to as a BSR here, despite its lack of seafloor mimicking geometry.

The interior of the bell-shaped BSR is also transparent. While some stratal reflections appear to terminate at this reflection (1430 $\mathrm{m}$ depth in the lower part of Fig. 2), there are a series of reflections that pass through the area outlined by the bell-shaped reflection with minimal attenuation but significant velocity pushdown (Hutchinson et al., 2005). A pushdown from 1433-1466 $\mathrm{m}$ at 1300 m water depth (Fig. 2 top and center, and Fig. 3), represents a $30 \%$ drop in sound speed, for which free gas in the shallow section is the most likely explanation. We assume the amount of gas responsible for the pushdown is of low enough concentration that the resulting attenuation does not mask the reflectors passing below the mound. Also, the presence of stratal reflections passing through the bell-shaped reflection indicates that the strata there have not been obliterated by fluidization. This indicates that the bell-shaped reflection is not the outer edge of a mud diapir. The inferred conduit supplying the fluid and mud is too narrow to be detected in any of the three data sets and reaches the seafloor with minimal disruption of the shallow strata.

The seismic expression of the gassy sediments around Mound $\mathrm{F}$ is distinctly different in DTAGS and GI-gun data than in the WG data. The apex of the BSR below Mound F is the brightest feature in the WG data. It is just barely visible at $1335 \mathrm{~m}$ depth in the GIgun data (Fig. 3, open arrows) and appears only as a deeper, 
diffuse cloud in the DTAGS data. In DTAGS line GM05-2 only the shoulder of the event was traversed (see DTAGS track line in Fig. 1). Not only does the seismic expression of the BGHS perturbation differ with frequency, it also appears to vary with direction. In the cross-line profiles over Mound $F$ the apex is much clearer in both the DTAGS and GI-gun data (Fig. 4, open arrows), but the high-amplitude, coherent events that were pushed down in Fig. 3 cannot be traced below the mound. Why these events are more continuous and distinct in one direction than the other is not clear.

The DTAGS data exhibit distinct diffraction hyperbolas at Mound $\mathrm{F}$ and throughout the profiles. Examples include diffractions located mostly to the NW (Fig. 3, filled arrows) and SW of Mound F (Fig. 4, filled arrows), sometimes in such close proximity to each other they interfere significantly, forming swarms. The apex directly below the mound in Fig. 4 (open arrow) is an example of a very large swarm of interfering diffraction hyperbolas. Similar swarms of diffractions can also be seen throughout the DTAGS profiles, with varying levels of mutual interference, especially near the depth of the BGHS. To cause diffractions of this nature the diffractors must be constrained laterally to only a few traces (tens of meters) and constrained vertically to less than $10 \mathrm{~m}$. In the unmigrated DTAGS data the isolated anomalies exhibit diffraction hyperbolas and are easy to identify. In the migrated data (GI-gun and WG data), the reflectivity anomalies are present, but more difficult to detect.

\subsection{Mound D}

The morphology of Mound D is significantly different than that of Mound $\mathrm{F}$. The reverse polarity seafloor reflection at Mound D in the WG data (Fig. 2) suggests that the BGHS has been perturbed all the way to the seafloor (Snyder et al., 2004). This is confirmed in the higher frequency data (Figs. 2, 5, and 6), where no bell-shaped reflector or clear apex can be detected. The DTAGS data in Fig. 5 show numerous strong diffractions within $20 \mathrm{~m}$ of the seafloor, and there are no reflections in any data set that can be traced below Mound D; the gas at the surface appears to obliterate all underlying reflectivity in DTAGS line GM05-1 (Fig. 5), and cross-line GM05-4 (Fig. 6).

Approximately $700 \mathrm{~m}$ to the SE of Mound D and at $\sim 10 \mathrm{mbsf}$ (Fig. 5) there appears to be a similar swarm of gas-related diffractions in the DTAGS data, although with no resolvable seafloor manifestation. The section below this swarm is similar in transparency to the section directly below Mound D. The event can be seen in both the DTAGS and GI-gun profiles, although in the migrated GI-gun data the feature manifests as a small bright spot (Fig. 5).

\subsection{Mound E}

The last mound discussed here, for which we present only DTAGS data, is Mound E (Fig. 6), whose morphology is similar to that of Mound F. At $\sim 900 \mathrm{~m}$ wide, Mound $\mathrm{E}$ is somewhat broader than Mound $\mathrm{F}$ and exhibits two apparent gas accumulations directly below the mound (Fig. 6, open arrows), the shallower accumulation being about the same depth $(40 \mathrm{~m})$ as the accumulation directly below Mound F. The sediments below Mound E are more seismically transparent than those at Mound F. The most identifiable events are the two anomalies directly below the mound. There also appear to be fewer, if any, isolated diffraction hyperbolas, even at a depth corresponding to the regional BGHS. In contrast to the areas further to the north and east, there appears to be little indication of gas accumulated below the BGHS.

\section{Discussion}

The lack of laterally consistent, strong reflections in the seismic profiles presented here reduces the effectiveness of conventional techniques for quantitatively estimating gas and gas hydrate concentrations. Inversion of seismic CMP gathers (e.g., Singh et al., 1993) or application of amplitude vs. offset (AVO; e.g., Ecker et al., 1998) techniques requires specular reflection off a planar surface to quantitatively extract seismic velocities and densities. For the strata exhibited here, we must instead rely more on the positions of reflectivity anomalies to infer the locations of gas and gas hydrate.

\subsection{Frequency-dependent reflectivity}

We here consider the anomalies marked with open arrows in Figs. 3 and 4 and the filled rectangles in the lower left corners indicating the volume over which each seismic response is averaged. In the DTAGS data we detect a swarm of small, interfering reflections and diffractions, suggesting individual diffractors (possible accumulations of gas) at sub-wavelength scales. In the GI-gun data this swarm is averaged over a larger volume and is relatively weak, suggesting destructive interference at GI-gun scales. Migration of the GI-gun data may also degrade the higher frequency content in the data set. In the WG data (Fig. 2) the response from this accumulation is extremely strong, suggesting constructive interference on this scale. Similar scale dependence is seen the seafloor on top of Mound D. Here the DTAGS response is shown in Figs. 5 (left) and 6 (right), the GI-gun response in Fig. 5 (right), and the WG response in Fig. 2 to the GI-gun response in Fig. 5, and the WG response in Fig. 2. Scale dependence is also seen near the BGHS just to the northwest of Mound $\mathrm{F}$ where the apparent gas accumulation appears as a BSR in the WG data (Fig. 2) and as a diffraction swarm in DTAGS data (Fig. 3, left).

A somewhat different phenomenon occurs $\sim 400 \mathrm{~m}$ to the northwest of Mound $\mathrm{F}$ at a depth of $1450 \mathrm{~m}$. The WG data (Fig. 2) exhibit apparent high-amplitude points (bright spots), suggesting a diffractor distribution that is much smaller than the first Fresnel zone. This is confirmed in the DTAGS and GI-gun data at Mound F (Figs. 3 and 4), which exhibit more continuous reflections. These reflections are some of the few that are visible at all in the DTAGS sections near the mounds, and are likely enhanced by gas. The gas appears as a point in large Fresnel-zone data and as coherent reflectors in small Fresnel-zone data.

The significantly different seismic responses observed in these three data sets are consistent with a model of small gas accumulations configured as point scatterers. We hypothesize that the gas exists in pockets or accumulations that are small compared to the resolution of the ensonifying system. The accumulations need not completely displace the sediment and may only occupy the pore space within a given volume of sediment. When the accumulations are arranged such that they interfere constructively for the first Fresnel zone for a given system, as in the case of the bright spot directly below Mound F in the WG data, a strong, coherent reflection is observed. When the accumulations are arranged such that the interference is not coherent, we see multiple, interfering reflections as in the DTAGS data directly below Mound F.

A key point to this argument is determining if the diffractors are likely to be gas. Unfortunately, their small size makes any direct measurement or estimate other than the interpretation from seismic data unlikely. The diffractions are of similar amplitude and form and exist both within and outside the expected regional zone of gas hydrate stability. The diffractions lie in sediments at the bottom of the distal, nearly flat, deep-water portion of a submarine canyon, but must be caused by abrupt lateral and vertical changes (less than a few meters in scale). 
No evidence of coherent slumps or clasts is seen in any of the seismic sections or piston cores acquired in the vicinity of the mounds, so we assume the diffractions are not from sharp edges of disaggregated blocks. In addition, no evidence of coarse sediments has been found, and there is no unambiguous evidence of distinct channels in the sediment. Thus, we also assume that laterally variable channel deposits do not cause the diffractions.

Conversely, there is very strong evidence for free gas in the seismic sections. Gas-phase methane is the most plausible explanation for the velocity pushdown below Mound $F$ where we see a swarm of diffractions. Also, the reversed-polarity BSR that lies northwest of Mound $\mathrm{F}$ manifests as a diffraction swarm in the DTAGS data in Fig. 3. Gas is also the most likely reason for the reversed-polarity reflection at the seafloor at Mound D (Fig. 2), which is also associated with a swarm of diffractions in DTAGS data (Fig. 5). Although gas hydrate and calcium carbonate could also cause diffractions, free gas exhibits by far the largest acoustic impedance contrast. We therefore assume that the diffractions of similar amplitude and form to those mentioned above are caused by gas. When the diffractions occur above the regional BGHS, we assume that excess heat and/or high salinity pore water is retarding the formation of gas hydrate.

\subsection{Seismic modeling}

To test whether small gas accumulations acting as point scatterers could cause the seismic responses observed in all three data sets, we modeled the data using the arrangements of scatterers shown in Fig. 7a. We assume the point scatterers (gas accumulations) can be considered Huygens secondary scatterers, as is typically done in Kirchoff migration of seismic data (e.g., Yilmaz, 1987, p. 252). Fig. 7a shows a series of point scatterers whose position and relative strength were taken from the seafloor reflection of the DTAGS data over Mound F between 1300 and $1320 \mathrm{~m}$ deep. We included some isolated, point scatterers intended to represent sub-surface gas accumulations (filled arrow). We also included a series of point scatterers with randomly assigned strengths aligned $0.375 \mathrm{~m}$ apart vertically and $1.5 \mathrm{~m}$ apart laterally, with a larger-scale (tens of meters) arrangement intended to mimic the apex of the bell-shaped reflector seen in the WG data in Fig. 2 (Fig. 7, open arrow). Fig. 7b, c, and d show the modeled response from DTAGS (150 $\mathrm{m}$ altitude), the GI-gun (1300 $\mathrm{m}$ altitude) and large airgun array (1300 $\mathrm{m}$ altitude), respectively.

In each case the modeled and observed seismic responses are similar (compare Fig. 7b and c with Fig. 4 and Fig. 7d with Fig. 2). The simulated DTAGS data exhibit a swarm of interfering diffraction hyperbolas similar to that seen in the actual DTAGS data in Fig. 4, upon which the geometry of the scatterers was based. The interference pattern is also similar to diffraction swarms below Mounds D and E (Fig. 6). The simulated large air-gun array data exhibit a strong, coherent, reversed-polarity reflection, very similar to the field data (Fig. 2), and the simulated GI-gun data exhibit a coherent reflection, significantly weaker than the seafloor reflection, with a polarity barely identifiable as reversed, just as seen in the actual observations (Fig. 4).

We conducted additional simulations to determine the seismic response from a model in which the gas accumulations (scatterers) directly below the mound are arranged as would be expected from
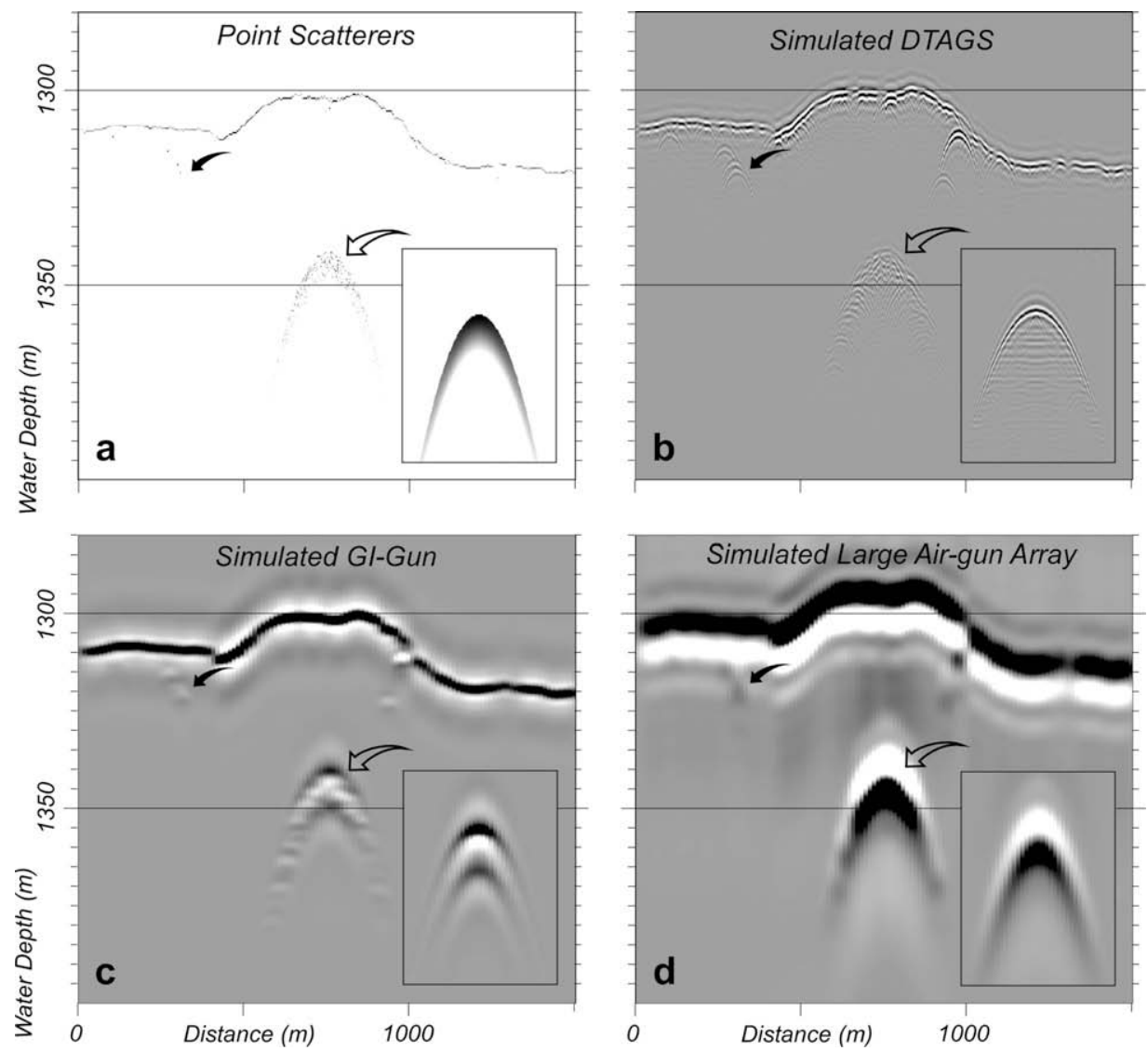

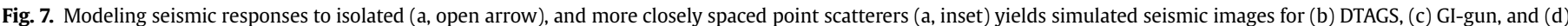

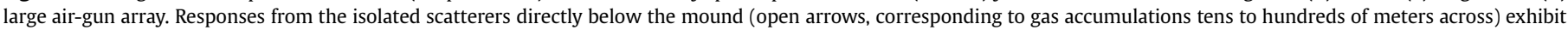

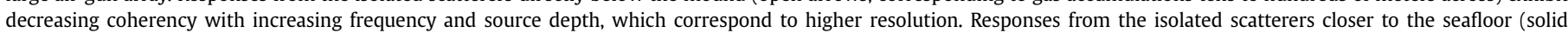

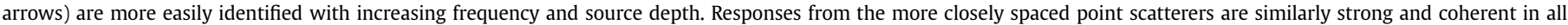
sections (insets in b-d). 


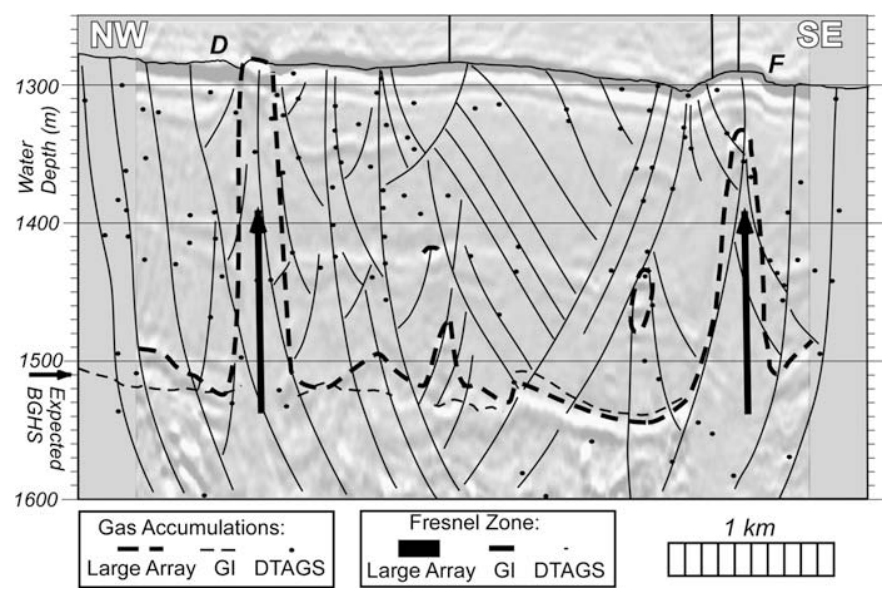

Fig. 8. The location of anomalous reflectivity interpreted as gas is shown for each seismic data set: large air-gun array (heavy dashed curve), GI-gun (thin dashed curve), and DTAGS data (black circles). The data are consistent with two modes of gas and/or gas hydrate emplacement from upward advection of fluids-one in which fluid flux occurs along a filamentous network of conduits (fine black curves), and one in which significant heat, methane, and some sediment are expelled through the seafloor (arrows). Interpretively mapped faults based on all three data sets (fine black curves) illustrate the likely style of some of the filamentous fault/conduits.

a volume of sediment within which gas is more uniformly distributed (Fig. 7a inset). In this case the effective scatterers are close enough that they interfere constructively even at scales resolvable with DTAGS. This results in a strong, coherent reflection in the simulated DTAGS data (Fig. 7b inset). In the simulated GI-gun data, this reflection is stronger and more coherent than for the simulation using more isolated scatterers (Fig. 7c inset). For the simulated large air-gun response, the two models of gas distribution yield nearly identical responses.

The modeling results suggest that anomalies that can cause high-amplitude, reversed-polarity reflections in the WG image (i.e., gas accumulations) may appear very differently-as a weakly reflective swarm of interfering diffractions with no identifiable polarity - in the DTAGS image. In the particular case modeled, the anomalies are almost certainly caused by gas, and the individual gas accumulations are on the order of meters apart, too isolated to interfere constructively in the DTAGS data and too close to be resolvable with the GI-gun data.

The seismic modeling results are consistent with a diffusiondominated system responsible for the bright, reversed-polarity reflection near the expected BGHS, interrupted by multiple instances of focused advection. If this model is accurate, we would expect the gas accumulations to lie along, or at least in close proximity to those conduits, resulting in a seismic image with frequent abrupt edges and point diffractions. Such a pattern is consistent with our seismic observations throughout the mound area, and similar to the pattern reported by others using highresolution techniques in this general area (e.g., Cooper and Hart, 2003).

\subsection{Methane distribution and transport}

Advective transport requires high permeability conduits, but permeability cannot be determined from seismic data directly, even in the case of the conduits associated with the mounds. However, we know that faults can act as high permeability conduits (e.g., Roberts et al., 1996), and we know faults can be inferred from seismic data. If we assume that the gas-related diffractions lie on or near fault controlled conduits, then we may be able to identify the style of faulting responsible for the advection, if not the actual faultconduits.
An interpretive estimate of the location of faults in the transect between Mounds D and F is shown as fine black curves in Fig. 8, superimposed on the WG data, representing a fine scale, near vertical, pervasive network of potential fluid conduits. The interpretation of these faults was based on lateral changes in stratal reflection strength, dip, or both in all three seismic data sets. The WG, GI-gun, and DTAGS data constrain the location of gas at various scales as shown in Fig. 8. The curves interpreted from the WG and GI-gun data delineate the uppermost bright and/or reversedpolarity reflection corresponding to gas (the BSR). The filled circles correspond to apexes of diffractions in the DTAGS data. Conduits of the type shown in Fig. 8 have recently been imaged in three dimensions at cold seeps in similar, deep-water, fine-grained sediments by Hornbach et al. (2007) and are consistent with the highly fractured seafloor seen in the side-scan data in this area (Hart et al., 2008).

This model of gas accumulation at various locations along filamentous faults is not consistent with a single level above which methane is stable as hydrate and below which methane is stable as gas. Instead, free gas near the seafloor implies a dynamic system where warm and/or saline fluids may create a far narrower, more ephemeral perturbation to the stability zone than can be imaged with any known technique.

In such a system the localized gas accumulations larger than a few meters and located within the nominal gas hydrate stability zone would be detectable only in small Fresnel-zone data. The larger, more laterally consistent gas accumulations above the expected BGHS could be seen as anomalously bright, laterally coherent events in large Fresnel-zone data. The large-scale perturbations associated with Mounds F and D are easily resolvable in the WG data, as is the BSR that we assume lies at the BGHS just to the northwest of Mound F. The perturbed BSR and coincident BGHS represent the top of gas at this larger scale (Fig. 8). However, narrow conduits, away from those associated with the mounds, may result in gas accumulations that cannot be fully resolved with any available system, but still contribute to the transport of methane through the sediment.

A model of intense, vertical advective flux at the mounds, combined with dispersed, filamentous advective flux away from the mounds and background diffusive transport is also consistent with other data. Geochemical and electromagnetic observations show significant lateral variability on and near Mound $\mathrm{F}$ (Coffin et al., 2008; Ellis et al., 2008). However, despite the assumed presence of dispersed advective conduits, the most intense instantaneous flux to the ocean appears to occur at mounds, where the mounds themselves, as well as a mudflow visible in side-scan data (Hart et al., 2008) suggest flux energetic enough to mobilize sediment. We cannot say from the data discussed here which mode of advection results in a greater methane transport over geologic time.

\section{Conclusions}

In the shallow sediments of the Mississippi Canyon floor, we observe strong frequency-dependent reflectivity in an otherwise weakly reflective section of sediment. Modeling of the three kinds of seismic data available in this area suggests that small accumulations of free gas, on the order of meters apart, are responsible for swarms of interfering diffractions in high-resolution data, and strong, continuous, reversed-polarity reflections in surface-towed air-gun data.

Although individual fault traces are not imaged in the seismic data directly, observations and modeling are consistent with fine scale faulting as a possible source of filamentous hydraulic conductivity by which advecting pore fluids emplace methane and/or methane hydrate in the shallow sediments within accumulations 
less than a few meters wide. However, we also observe larger-scale (hundreds of meters wide) perturbations to the base of gas hydrate stability directly below seafloor mounds similar to that shown by Wood et al. (2002), and consistent with high volume, turbulent, eruptive flow. A bright, reversed-polarity reflection at the BGHS, a feature expected for diffusion-related methane migration, suggests that both modes of advective transport take place against a background of diffusion-dominated transport.

\section{Acknowledgements}

The authors wish to thank B. Dugan, J. Childs, G. Barth, and one anonymous reviewer for excellent comments that significantly improved the manuscript. This work was funded through ONR program element 61153N, and U.S. Department of Energy Grant DE-A126-97FT3423.

\section{References}

Brooks, J.M., Kennicutt, M.C., Fay, R.R., MacDonald, I.R., Sassen, R., 1984. Thermogenic gas hydrates in the Gulf of Mexico. Science 225, 409-411.

Brown, K.M., Bangs, N.L., Froelich, P.N., Kvenvolden, K.A., 1996. The nature, distribution, and origin of gas hydrate in the Chile triple junction region. Earth and Planetary Science Letters 139, 471-483.

Claypool, G.E. (Ed.), 2006. Cruise Report: the Gulf of Mexico Gas Hydrate Joint Industry Project, Covering the Cruise of the Drilling Vessel Uncle John, Mobile, Alabama to Galveston, Texas, Atwater Valley Blocks 13/14 and Keathley Canyon Block 151, 17 April to 22 May, 2005. Department of Energy. Available from: http://www.netl.doe.gov/technologies/oil-gas/publications/Hydrates/reports/ GOMJIPCruise05.pdf, 58 pp.

Coffin, R.B., Gardner, J., Pohlman, J., Downer, R., Wood, W., 2006. Methane Hydrate Exploration, Atwater Valley, Texas-Louisiana Shelf: Geophysical and Geochemical Profiles US Naval Research Laboratory Technical Memorandum, NRL/MR/6110-06-9002.

Coffin, R.B., Hamdan, L., Plummer, R., Smith, J., Gardner, J., Wood, W.T., 2008. Analysis of methane and sulfate flux in methane charged sediments from the Mississippi Canyon, Gulf of Mexico. Marine and Petroleum Geology 25, 977-987.

Cooper, A., Hart, P.E., 2003. High-resolution seismic investigation of the Northern Gulf of Mexico gas-hydrate stability zone. Marine and Petroleum Geology 19, 1275-1293.

Dickens, G.R., Castillo, M.M., Walker, J.C.G., 1997. A blast of gas in the latest Paleocene; simulating first-order effects of massive dissociation of oceanic methane hydrate. Geology 25, 259-262.

Domenico, S.N., 1974. Effect of water saturation on seismic reflectivity of sand reservoirs encased in shale. Geophysics 39, 759-769.

Ecker, C., Dvorkin, J., Nur, A., 1998. Sediments with gas hydrates: internal structure from seismic AVO. Geophysics 63, 1659-1669.

Ellis, M., Evans, R.L., Hutchinson, D., Hart, P., Gardner, J., Hagen, R., 2008. Electromagnetic surveying of seafloor mounds in the Gulf of Mexico. Marine and Petroleum Geology 25, 960-968.
Hart, P.E., Hutchinson, D.R., Gardner, J., Carney, R.S., Fornari, D., 2008. A photographic and acoustic transect across two deep-water seafloor mounds, Mississippi Canyon, northern Gulf of Mexico. Marine and Petroleum Geology 25, 969-976.

Hilterman, F.J., 1982. Interpretive lessons from three-dimensional modeling. Geophysics 47, 784-808.

Hornbach, M.J., Ruppel, C., Van Dover, C.L., 2007. Three-dimensional structure of fluid conduits sustaining an active deep marine cold seep. Geophysical Research Letters 34, L05601, doi:10.1029/2006GL028859.

Hutchinson, D.R., Hart, P.E., 2004. Cruise report for G1-03-GM USGS gas hydrates cruise, R/V Gyre, 1-14 May, 2003, Northern Gulf of Mexico. U.S. Geological Survey Open File Report OF 03-474, 103 pp.

Hutchinson, D.R., Snyder, F., Hart, P.E., Ruppel, C.D., Pohlman, J., Wood, W.T. Coffin, R.B., Edwards, M., 2005. Geologic and site survey setting for JIP Gulf of Mexico gas hydrate drilling. EOS, Transactions, American Geophysical Union 86 (52). Abstract OS31D-01.

Kennett, J.P., Cannariato, K.G., Hendy, I.L., Behl, R.J., 2002. Methane Hydrates in Quaternary Climate Change: the Clathrate Gun Hypothesis. AGU, Washington, DC, 216 pp.

MacDonald, I.R., Guinasso, N.L., Sassen, R., Brooks, J.M., Lee, L., Scott, K.T., 1994. Gas hydrate that breaches the sea floor on the continental slope of the Gulf of Mexico. Geology 22, 699-702.

Roberts, S.J., Nunn, J.A., Cathles, L., Cipriani, F.-D., 1996. Expulsion of abnormally pressured fluids along faults. Journal of Geophysical Research 101, 2823128252.

Roberts, H.H., Carney, R.S., 1997. Evidence of episodic fluid, gas, and sediment venting on the northern Gulf of Mexico continental slope. Economic Geology $92,863-879$.

Sassen, R., Joye, S., Sweet, S.T., deFreitas, D.A., Milkov, A.V., MacDonald, I.R., 1999. Thermogenic gas hydrates and hydrocarbon gases in complex chemosynthetic communities, Gulf of Mexico continental slope. Organic Geochemistry 30 , 485-497.

Singh, S.C., Minshull, T.A., Spence, G.D., 1993. Velocity structure of a gas hydrate reflector. Science 260, 204-207.

Snyder, F.F.C., Muller, L.K., Dutta, N., Hutchinson, D.R., Hart, P.E., Lee, M.W., Dugan, B., Ruppel, C., Woods, W.T., Coffin, R., Evans, R., Jones, E.H., 2004. Seismic analysis and characterization of gas hydrates in the Northern Deepwater Gulf of Mexico. AAPG Bulletin 88 (Suppl. 13). Available from: http://www.searchanddiscovery. com/documents/abstracts/annual2004/Dallas/Snyder.htm.

Vardaro, M.F., MacDonald, I.R., Bender, L.C., Guinasso, N.L., 2005. Dynamic processes observed at a gas hydrate outcropping on the continental slope of the Gulf of Mexico. Geo-Marine Letters 26, 6-15.

Wood, W.T., Gettrust, J.F., 2001. Deep-towed seismic investigations of methane hydrates. In: Paull, C.K., Dillon, W.P. (Eds.), Natural Gas Hydrates: Occurrence, Distribution and Detection. AGU Monograph Series, No. 124. AGU, Washington, D.C., pp. $165-178$.

Wood, W.T., Gettrust, J.F., Chapman, N.R., Spence, G.D., Hyndman, R.D., 2002. Decreased stability of methane hydrates in marine sediments owing to phaseboundary roughness. Nature 420, 656-660.

Wood, W.T., Gettrust, J.F., Spychalski, S.E., 2003. A new deep-towed, multi-channel seismic system. Sea Technology 44, 44-49.

Wood, W.T., Gardner, J., Hagen, R.A., Coffin, R.B., Pohlman, J.W., Hart, P.E., Hutchinson, D.R., 2004. Modeling heat and fluid flux of seafloor mounds in the Gulf of Mexico. EOS, Transactions, American Geophysical Union 85 (47). Abstract OS34B-08.

Yilmaz, O., 1987. Seismic data processing. SEG Investigations in Geophysics 2, 526 pp. 